\title{
Implementasi Algoritma Apriori Untuk Menentukan Stok Obat
}

\author{
Winanda Delrinata ${ }^{[1]^{*}}$, Fernando B Siahaan ${ }^{[2]}$ \\ Program Studi Ilmu Komputer STMIK Nusa Mandiri ${ }^{[1]}$, \\ Program Studi Sistem Informasi Universitas Bina Sarana Informatika ${ }^{[2]}$ \\ wdelrinata@gmail.com ${ }^{[1]}$,fernando.fbs@bsi.ac.id ${ }^{[2]}$
}

\begin{abstract}
The supply of drugs in a pharmacy is very important to maintain the fulfillment of consumer needs base $d$ on a doctor's prescription. Problems arise due to limitations on the expiry date of each drug, this needs to be overcome so that there is no buildup of drug stocks at the pharmacy so that it causes losses because there are types of drugs that have expired in sufficient quantities, therefore we need data mining that can determine which pattern of drug type works best, using a priori algorithm. The association method is needed to see the correlation between a number of attributes for example if a consumer buys drug A then he will buy drug $B$ as well. A priori analysis to determine the minimum conditions for support and confidence. The conclusion of this research is that if you buy amlodipine $5 \mathrm{mg}$, you will buy sanmol, this is obtained from $33.33 \%$ support and $66.66 \%$ confidence, if you buy $500 \mathrm{mg}$ amoxan, you will buy sanmol with a support value of $41.66 \%$ and confidence $71,42 \%$ and if you buy sanmol, you will buy amoxan $500 \mathrm{mg}$ with a support value of $41.66 \%$ and confidence $62.50 \%$.
\end{abstract}

Keywords - datamining, a priori algorithm, drug inventory

Abstrak-Persediaan obat pada sebuah apotek sangat penting untuk menjaga terpenuhinya kebutuhan konsumen berdasarkan resep dokter. Permasalahan timbul karena adanya keterbatasan pada tanggal kadaluwarsa dari masing-masing obat, hal ini perlu untuk diatasi agar tidak terjadi penumpukan stok obat pada apotek sehingga menyebabkan kerugian karena terdapat jenis obat yang sudah kadaluwarsa dalam jumlah cukup banyak, oleh karena itu diperlukan data mining yang dapat menentukan pola jenis obat mana yang paling laku, dengan menggunakan algoritma apriori. Metode asosiasi diperlukan untuk melihat korelasi antara sejumlah atribut misal jika konsumen membeli obat A maka dia akan membeli obat B juga. Analisa apriori untuk menentukan syarat minimum untuk support dan confidence. Kesimpulan pada penelitian ini adalah jika membeli amlodipine $5 \mathrm{mg}$ maka akan membeli sanmol hal ini didapat dari support $33,33 \%$ dan confidence $66,66 \%$, jika membeli amoxan $500 \mathrm{mg}$ maka akan membeli sanmol dengan nilai support $41,66 \%$ dan confidence $71,42 \%$ dan jika membeli sanmol maka akan membeli amoxan $500 \mathrm{mg}$ dengan nilai support $41,66 \%$ dan confidence $62,50 \%$.

Kata Kunci-data mining, algoritma apriori, persediaan obat

\section{PENDAHULUAN}

Pada sebuah Apotek persediaan obat menjadi hal yang paling penting agar dapat melayani konsumen. Konsumen yang datang pada apotek berdasarkan resep dokter untuk membeli obat atau membeli tidak mnggunakan resep dokter. Untuk itu persediaan obat perlu diperhatikan agar obat yang dicari konsumen tidak kosong. Toko perlu menyediakan berbagai macam peralatan tulis agar dapat mengetahui tingkat pembelian pada produk-produk yang lebih sering dibeli oleh konsumen[1]. Penerapan data mining di bidang kesehatan untuk persediaan alat kesehatan merupakan faktor yang mempengaruhi kualitas pelayanan pada rumah sakit[2]. Perlu dilakukan startegi jitu untuk meningkatkan penjualan obat agar stok selalu tersedia sehingga diperlukan informasi tentang jenis obat yang paling laku terjual[3]. Stok barang perlu diperhatikan oleh sebuah toko agar jumlah barang yang tersedia tidak lebih banyak dari yang dibeli konsumen dikarenakan barang akan kadaluwarsa sehngga menyebabkan kerugian pada pihak toko, namun sebaliknya toko jangan mempunyai stok yang minim sehingga saat konsumen ingin membeli barang ternyata barang tidak ada. Untuk itu diperlukan sistem cerdas yang dapat mengetahui ketersediaan stok barang[4]. Persaingan yang ketat mengharuskan pelaku usaha melakukan analisa terhadap ketersediaan barang yang dijual supaya kebutuhan konsumen dapat selalu terpenuhi[5]. Proses penjualan pada supermarket terjadi secara continue sehingga jumlah transaksi selalu bertambah, data penjualan tersebut tentunya dapat dimanfaatkan untuk dipelajari sebagai strategi penjualan pada tahun mendatang dengan harapan terjadinya peningkatan penjualan pada tahun-tahun mendatang[6].

Data mining diperlukan untuk mengetahui buku yang dibeli secara bersamaan, kebiasaan konsumen untuk melakukan pembelian buku apa saja yang sering dilakukan, analisa kebiasaan pelanggan dapat dilakukan dengan meganalisa keranjang pasar (market basket analysis) tujuannya menemukan produk-produk yang sering dibeli secara bersamaan[7]. Metode asosiasi atau association rule mining diperlukan untuk melihat korelasi atau hubungan asosiasi antara sejumlah atribut, dengan menggunakan algoritma apriori. Algoritma apriori termasuk jenis aturan asosiasi untuk menemukan frequent item set pada sekumpulan data. Analisis apriori untuk menentukan semua aturan apriori 
yang memenuhi syarat minimum untuk support dan confidence [8].

Penelitian ini ingin mengatasi permasalahan tentang ketersediaan stok obat di apotik dengan menganalisis pembelian obat yang dilakukan oleh konsumen, misal jika konsumen membeli obat "A" maka dia juga akan membeli obat "B". Tujuan penelitian ini membantu pihak apotek "CNC Farma" didalam mengendalikan persediaan obat agar obat tidak kadaluwarsa sehingga merugikan apotek sendiri.

\section{BAHAN DAN METODE}

Data mining merupakan suatu proses otomatis terhadap data yang sudah ada, diproses berupa data yang sangat besar, tujuan data mining adalah untuk mendapatkan hubungan yang dapat memberikan indikasi bermanfaat[9]. Knowledge discovery in databases (KDD) sering dipakai secara bergantian untuk menjelaskan suatu proses penggalian informasi secara tersembunyi. Tahapan proses Knowledge discovery in databases dapat dilihat pada gambar1 dibawah ini.

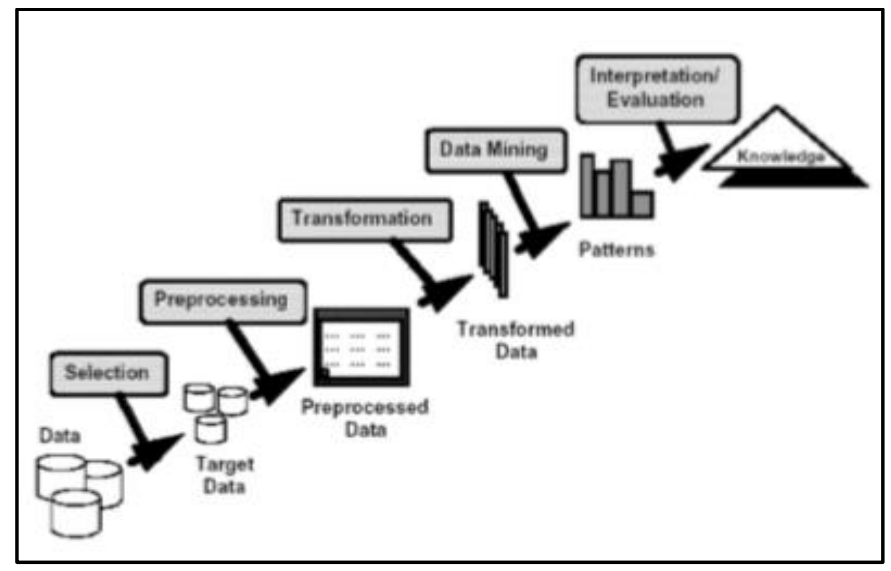

Gambar 1. Tahapan pada Knowledge discovery in databases (KDD)

Tahapan pada gambar 1 tersebut dapat dijabarkan sebagai beikut[10]:

\section{1) Data selection}

Dilakukan penyeleksian dari sekumpulan data besar yang akan digali sebagai tahap awal.

2) Pre-processing/Cleaning

Proses pembersihan (cleaning) perlu dilakukan untuk membuang data yang tidak digunakan atau data terduplikasi sehingga data menjadi lebih sedikit namun mempunyai arti.

3) Transformation

Proses transformasi pada data yang telah dipilih sehingga data tersebut sudah sesuai untuk proses data mining.

4) Data mining

Proses mencari pola pada data terpilih dengan menggunakan metode tertentu, algoritma yang dipakai menyesuaikan dengan tujuan dan proses KDD secara keselurhuan.

5) Interpretation/Evaluation

Pola informasi yang dihasilkan dari data mining ditampilkan dalam bentuk yang dapat dipahami oleh pihak yang berkepentingan.
Algoritma apriori adalah algoritma yang paling sesuai untuk menemukan pola frekuensi tinggi[11]. Tahapan dalam algortima apriori adalah sebagai berikut:

1. Pembentukan kandidat item set (k-itemset) dibentuk dari kombiasi (k-1) itemset yang didapat dari iterasi sebelumnya

2. Penghitungan support dari tiap k-itemset. Support dari tiap kandidat $\mathrm{k}$ itemset didapat dengan men-scan database untuk menghitung jumlah transaksi yang memuat semua item didalam kandidat $\mathrm{k}$-item tersebut.

3. Tetapkan pola frekuensi tinggi. Pola frekuensi tinggi yang memuat $\mathrm{k}$ item ditetapkan dari kandidat k-itemset yang supportnya lebih besar dari minimum support.

4. Bila tidak didapat pola frekuensi tinggi baru maka seluruh proses dihentikan, bila tidak maka $\mathrm{k}$ ditambahkan satu dan kembali ke bagian 1.

\section{a. Support}

Nilai support sebuah item diperoleh dengan menggunakan rumus:

$$
\begin{aligned}
& \text { Support }(\mathrm{A}, \mathrm{B})=\mathrm{P}(\mathrm{A} \cap \mathrm{B}) \\
& \operatorname{Support}(A, B)=\frac{\sum \text { Transaksi mengandung } A \text { dan } B}{\sum \text { Transaksi }}
\end{aligned}
$$

Penjelasan:

$\sum$ Transaksi mengandung $\mathrm{A}$ dan $\mathrm{B}=$ banyaknya item $\mathrm{A}$ dan item B secara bersamaan dalam transaksi keseluruhan

$\sum$ Transaksi $=$ jumlah total keseluruhan transaksi

\section{b. Confidence}

Confidence dari association rule adalah urutan ketepatan suatu rule, yaitu presentasi transaksi dalam database yang mengandung A dan mengandung B. Confidence dapat mengukur kuatnya hubungan antar item dalam association rule. Cara menghitung confidence dengan rumus:

Confidence $=\mathrm{P}(\mathrm{B} \mid \mathrm{A})$

$$
\text { Confidence }=\frac{\sum \text { Transaksi mengandung A dan } B}{\sum \text { Transaksi mengandung } A}
$$

Penjelasan:

$\sum$ Transaksi mengandung $\mathrm{A}$ dan $\mathrm{B}=$ banyaknya muncul item A dan item B secara bersamaan dalam transaksi keseluruhan.

$\sum$ Transaksi A = banyaknya muncul item A pada keseluruhan transaksi.

Penelitian ini dilakukan pada Apotek CNC Farma yang berlokasi di Bekasi dengan mengumpulkan data transaksi obat yang terjual selama satu tahun (dari September 2016 sampai Agustus 2017) dimana ada 161 jenis obat yang terjual. Penelitian ini menggunakan algoritma apriori untuk mengetahui jenis obat mana yang paling sering dibeli konsumenn. 


\section{HASIL DAN PEMBAHASAN}

A. Data Penjualan Obat dalam setahun

Data diambil dari transaksi penjualan obat selama satu tahun dari bulan September 2016 sampai Agustus 2017 yang disajikan pada tabel dibawah ini.

Tabel 1. Penjualan Obat Bulan September 2016

\begin{tabular}{|c|l|l|}
\hline No & \multicolumn{1}{|c|}{ Data Obat } & \multicolumn{1}{c|}{ Total } \\
\hline 1 & Clindamycin 300mg & $175 \mathrm{Kaps}$ \\
\hline 2 & Sanmol tab & $132 \mathrm{tab}$ \\
\hline 3 & Becom C kapl & $130 \mathrm{kapl}$ \\
\hline 4 & Amlodipine 5mg tab & $125 \mathrm{tab}$ \\
\hline 5 & Amoxicillin 500mg & $125 \mathrm{tab}$ \\
\hline 6 & Cataflam 50 mg & $105 \mathrm{tab}$ \\
\hline 7 & Neurobion Forte tab & $100 \mathrm{tab}$ \\
\hline 8 & Caviplex & $95 \mathrm{kapl}$ \\
\hline 9 & Dexamethasone $0.5 \mathrm{mg}$ & $95 \mathrm{tab}$ \\
\hline 10 & Vitazym tab & $70 \mathrm{tab}$ \\
\hline 11 & Mefinal tab & $65 \mathrm{tab}$ \\
\hline 12 & Imboost tab & $60 \mathrm{tab}$ \\
\hline 13 & Renitidine tab & $60 \mathrm{tab}$ \\
\hline 14 & Asam mefenamat $500 \mathrm{mg}$ & $55 \mathrm{tab}$ \\
\hline 15 & Imbost Force Tab & 50 tab \\
\hline
\end{tabular}

Tabel 2. Penjualan Obat Bulan Oktober 2016

\begin{tabular}{|c|l|l|}
\hline No & \multicolumn{1}{|c|}{ Data Obat } & \multicolumn{1}{c|}{ Total } \\
\hline 1 & Clindamycin 300mg & $144 \mathrm{kaps}$ \\
\hline 2 & Sanmol tab & $139 \mathrm{tab}$ \\
\hline 3 & Neurobion Forte tab & $125 \mathrm{tab}$ \\
\hline 4 & Dexamethasone $0.5 \mathrm{mg} \mathrm{tab}$ & $93 \mathrm{tab}$ \\
\hline 5 & Amoxan 500mg tab & $80 \mathrm{tab}$ \\
\hline 6 & Becom-C kapl & $70 \mathrm{kapl}$ \\
\hline 7 & Dexamethasone $0.75 \mathrm{mg} \mathrm{tab}$ & $60 \mathrm{tab}$ \\
\hline 8 & Mefinal tab & $60 \mathrm{tab}$ \\
\hline 9 & Imboost tab & $60 \mathrm{tab}$ \\
\hline 10 & Ester-C kapl & $60 \mathrm{kapl}$ \\
\hline 11 & Cataflam 50mg & 50 tab \\
\hline 12 & Neuralgin tab & 50 tab \\
\hline 13 & Omeprazole kaps & $40 \mathrm{kaps}$ \\
\hline 14 & Ponstan tab & 40 tab \\
\hline 15 & Mertigo tab & 40 tab \\
\hline
\end{tabular}

Tabel 3. Penjualan Obat Bulan November 2016

\begin{tabular}{|c|l|l|}
\hline No & \multicolumn{1}{|c|}{ Data Obat } & \multicolumn{1}{c|}{ Total } \\
\hline 1 & Amoxan 500mg kaps & $175 \mathrm{kaps}$ \\
\hline 2 & Sanmol tab & $127 \mathrm{tab}$ \\
\hline 3 & Amlodipine 5mg tab & $100 \mathrm{tab}$ \\
\hline 4 & Neurobion Forta tab & $95 \mathrm{tab}$ \\
\hline 5 & Clindamycin 300mg & $72 \mathrm{kaps}$ \\
\hline 6 & Rhinos SR kaps & $70 \mathrm{kaps}$ \\
\hline 7 & Simvastatin 20mg tab & 70 tab \\
\hline 8 & Cataflam 50mg & 60 tab \\
\hline 9 & Becom-C kapl & $60 \mathrm{kapl}$ \\
\hline 10 & Amlodipine 10mg tab & 60 tab \\
\hline 11 & Dexamethasone 0.5tab & 50 tab \\
\hline 12 & Imboost tab & 50 tab \\
\hline 13 & Ponstan tab & $45 \mathrm{tab}$ \\
\hline 14 & Amoxicillin 500mg & $45 \mathrm{kaps}$ \\
\hline 15 & Ciprofloxacin 500mg tab & 40 tab \\
\hline
\end{tabular}

Tabel 4. Penjualan Obat Bulan Desember 2016

\begin{tabular}{|c|l|l|}
\hline No & \multicolumn{1}{|c|}{ Data Obat } & \multicolumn{1}{c|}{ Total } \\
\hline 1 & Becom-C kapl & $180 \mathrm{kapl}$ \\
\hline 2 & Neurobion Forte tab & $130 \mathrm{tab}$ \\
\hline 3 & Amlodipine 5mg tab & $100 \mathrm{tab}$ \\
\hline 4 & Clindamycin 300mg kaps & $97 \mathrm{kaps}$ \\
\hline 5 & Paratusin tab & $90 \mathrm{tab}$ \\
\hline 6 & Amoxan 500mg kaps & $90 \mathrm{kaps}$ \\
\hline 7 & Ponstan tab & $90 \mathrm{tab}$ \\
\hline 8 & Imboost tab & $80 \mathrm{tab}$ \\
\hline 9 & Sanmol tab & $76 \mathrm{tab}$ \\
\hline 10 & Mefinal tab & $70 \mathrm{tab}$ \\
\hline 11 & Asam Mefenamat 500mg tab & $60 \mathrm{tab}$ \\
\hline 12 & Mertigo tab & $50 \mathrm{tab}$ \\
\hline 13 & Amoxicillin 500mg tab & $50 \mathrm{tab}$ \\
\hline 14 & Cefadroxil 500mg kaps & $40 \mathrm{kaps}$ \\
\hline 15 & Dolo Neurobion tab & $40 \mathrm{tab}$ \\
\hline
\end{tabular}

Tabel 5. Penjualan Obat Bulan Januari 2017

\begin{tabular}{|c|l|l|}
\hline No & \multicolumn{1}{|c|}{ Data Obat } & \multicolumn{1}{c|}{ Total } \\
\hline 1 & Sanmol tab & 148 tab \\
\hline 2 & Clindamycin 300mg & $136 \mathrm{kaps}$ \\
\hline 3 & Amoxan 500mg kaps & $125 \mathrm{kaps}$ \\
\hline 4 & Cataflam 50mg & $100 \mathrm{tab}$ \\
\hline 5 & Paratusin tab & 80 tab \\
\hline 6 & Rhinos SR kaps & $70 \mathrm{kaps}$ \\
\hline 7 & Becom-C & $65 \mathrm{kapl}$ \\
\hline 8 & Imboost tab & $60 \mathrm{tab}$ \\
\hline 9 & Dexamethasone 0.5mg & $55 \mathrm{tab}$ \\
\hline 10 & Cefadroxil 500mg & $50 \mathrm{kaps}$ \\
\hline 11 & Stimuno kaps & $50 \mathrm{kaps}$ \\
\hline 12 & Amlodipine 10mg tab & 50 tab \\
\hline 13 & Amlodipine 5mg tab & 50 tab \\
\hline 14 & Imboost Force tab & 40 tab \\
\hline 15 & Cefixime 200mg kaps & $40 \mathrm{kaps}$ \\
\hline
\end{tabular}

Tabel 6. Penjualan Obat Bulan Februari 2017

\begin{tabular}{|c|l|l|}
\hline No & \multicolumn{1}{|c|}{ Data Obat } & \multicolumn{1}{c|}{ Total } \\
\hline 1 & Neurobion Forte tab & $100 \mathrm{tab}$ \\
\hline 2 & Clindamycin 300mg & $96 \mathrm{kaps}$ \\
\hline 3 & Amlodipine 5mg tab & $95 \mathrm{tab}$ \\
\hline 4 & Amoxan 500mg kaps & $90 \mathrm{kaps}$ \\
\hline 5 & Cataflam 25mg tab & $70 \mathrm{tab}$ \\
\hline 6 & Epexol tab & $70 \mathrm{tab}$ \\
\hline 7 & Ponstan tab & $60 \mathrm{tab}$ \\
\hline 8 & Dexamethasone 0.5mg & $40 \mathrm{tab}$ \\
\hline 9 & Imboost tab & $38 \mathrm{tab}$ \\
\hline 10 & Mertigo tab & $30 \mathrm{tab}$ \\
\hline 11 & Cefadroxil 500mg & $30 \mathrm{tab}$ \\
\hline 12 & Asam Mefenamat 500mg & $30 \mathrm{tab}$ \\
\hline 13 & Mefinal tab & $30 \mathrm{tab}$ \\
\hline 14 & Dolo Neurobion tab & $30 \mathrm{tab}$ \\
\hline 15 & Acyclovir 400mg tab & $30 \mathrm{tab}$ \\
\hline
\end{tabular}

Tabel 7. Penjualan Obat Bulan Maret 2017

\begin{tabular}{|c|l|l|}
\hline No & \multicolumn{1}{|c|}{ Data Obat } & \multicolumn{1}{c|}{ Total } \\
\hline 1 & Amlodipine 5mg tab & 160 tab \\
\hline 2 & Sanmol Tab & 130 tab \\
\hline 3 & Amoxan 500mg kaps & $105 \mathrm{kaps}$ \\
\hline 4 & Neurobion Forte tab & $100 \mathrm{tab}$ \\
\hline 5 & Clindamycin 300mg & $90 \mathrm{kaps}$ \\
\hline 6 & Cataflam 50mg & 60 tab \\
\hline 7 & Becom-C kapl & $60 \mathrm{kapl}$ \\
\hline
\end{tabular}




\begin{tabular}{l}
\hline \hline \multicolumn{2}{|l|}{} \\
\begin{tabular}{|c|l|l|}
\hline 8 & Paratusin tab & 40 tab \\
\hline 9 & Neuralgin tab & 40 tab \\
\hline 10 & Imboost tab & 40 tab \\
\hline 11 & Dexteem plus tab & 40 tab \\
\hline 12 & Dexamethasone 0.5mg & 40 tab \\
\hline 13 & Cefadroxil 500mg & 40 tab \\
\hline 14 & Amoxicillin 500mg & 40 tab \\
\hline 15 & Stimuno kaps & $30 \mathrm{kaps}$ \\
\hline
\end{tabular}
\end{tabular}

Tabel 8. Penjualan Obat Bulan April 2017

\begin{tabular}{|c|l|l|}
\hline No & \multicolumn{1}{|c|}{ Data Obat } & \multicolumn{1}{c|}{ Total } \\
\hline 1 & Sanmol Tab & $145 \mathrm{tab}$ \\
\hline 2 & Becom-C kapl & $120 \mathrm{kapl}$ \\
\hline 3 & Amoxan 500mg kaps & $103 \mathrm{kaps}$ \\
\hline 4 & Ciprofloxacin 500mg tab & $95 \mathrm{tab}$ \\
\hline 5 & Amlodipine 10mg tab & $95 \mathrm{tab}$ \\
\hline 6 & Neurobion Forte tab & $90 \mathrm{tab}$ \\
\hline 7 & Clindamycin 300mg & $90 \mathrm{kaps}$ \\
\hline 8 & Rhinos SR kaps & $80 \mathrm{tab}$ \\
\hline 9 & Amlodipine 5mg tab & 80 tab \\
\hline 10 & Cataflam 50mg & $75 \mathrm{tab}$ \\
\hline 11 & Dexamethasone 0.75mg & $60 \mathrm{tab}$ \\
\hline 12 & Imboost tab & $60 \mathrm{tab}$ \\
\hline 13 & Legiron & $60 \mathrm{tab}$ \\
\hline 14 & Ponstan tab & 60 tab \\
\hline 15 & Mefinal tab & 55 tab \\
\hline
\end{tabular}

Tabel 11. Penjualan Obat Bulan Juli 2017

\begin{tabular}{|c|l|l|}
\hline No & \multicolumn{1}{|c|}{ Data Obat } & \multicolumn{1}{c|}{ Total } \\
\hline 1 & Amoxan 500mg kaps & $120 \mathrm{kaps}$ \\
\hline 2 & Sanmol Tab & $100 \mathrm{tab}$ \\
\hline 3 & Amlodipine 5mg tab & $95 \mathrm{tab}$ \\
\hline 4 & Becom-C kapl & $90 \mathrm{kapl}$ \\
\hline 5 & Lipitor 20mg & 60 tab \\
\hline 6 & Stimuno caps & $50 \mathrm{kaps}$ \\
\hline 7 & Rhinos SR kaps & $50 \mathrm{kaps}$ \\
\hline 8 & Imboost tab & $40 \mathrm{tab}$ \\
\hline 9 & Dexamethasone $0.5 \mathrm{mg}$ & $40 \mathrm{tab}$ \\
\hline 10 & Mefinter tab & 40 tab \\
\hline 11 & Clindamycin 300mg & $34 \mathrm{kaps}$ \\
\hline 12 & Premaston tab & 30 tab \\
\hline 13 & Amoxicillin 500mg & 30 tab \\
\hline 14 & Sumagesic tab & $30 \mathrm{tab}$ \\
\hline 15 & Cefadroxil 500mg & 30 tab \\
\hline
\end{tabular}

Tabel 12. Penjualan Obat Bulan Agustus 2017

\begin{tabular}{|c|l|l|}
\hline No & \multicolumn{1}{|c|}{ Data Obat } & \multicolumn{1}{c|}{ Total } \\
\hline 1 & Neurobion Forte tab & $120 \mathrm{tab}$ \\
\hline 2 & Amlodipine 5mg tab & $105 \mathrm{tab}$ \\
\hline 3 & Sanmol Tab & $95 \mathrm{tab}$ \\
\hline 4 & Clindamycin 300mg & $74 \mathrm{kaps}$ \\
\hline 5 & Amoxan 500mg kaps & $70 \mathrm{kaps}$ \\
\hline 6 & Mefinal tab & $65 \mathrm{tab}$ \\
\hline 7 & Ester-C kapl & $60 \mathrm{tab}$ \\
\hline 8 & Becom-C kapl & $50 \mathrm{kapl}$ \\
\hline 9 & Dexamethasone 0.5mg & $40 \mathrm{tab}$ \\
\hline 10 & Mertigo tab & $40 \mathrm{tab}$ \\
\hline 11 & Premaston tab & $30 \mathrm{tab}$ \\
\hline 12 & Cataflam 50mg & $30 \mathrm{tab}$ \\
\hline 13 & Dexamethasone 0.75 & $30 \mathrm{tab}$ \\
\hline 14 & Imboost tab & $30 \mathrm{tab}$ \\
\hline 15 & Stimuno caps & \multicolumn{2}{c|}{ aps } \\
\hline
\end{tabular}

\section{B. Pola Transaksi Penjualan Obat}

Berdasarkan data penjualan obat selama satu tahun didapatkan pola transaksi dengan menganalisa tiga macam obat seperti pada tabel 13 dibawah ini.

Tabel 13 Pola Transaksi Penjualan Obat selama satu tahun

\begin{tabular}{|c|c|}
\hline Bulan & Item Set \\
\hline 1 & Clindamycin 300mg kaps, Sanmol tab, Becom-C kapl \\
\hline 2 & Clindamycin 300mg kaps, Sanmol tab, Neurobion Forte tab \\
\hline 3 & Amoxan 500mg kaps, Sanmol tab, Amlodipine 5mg tab \\
\hline 4 & Becom-C kapl, Neurobion Forte tab, Amlodipine $5 \mathrm{mg}$ tab \\
\hline 5 & Sanmol tab, Clindamycin 300mg kaps, Amoxan 500mg kaps \\
\hline 6 & $\begin{array}{l}\text { Neurobion Forte tab, Clindamycin 300mg kaps, Amlodipine } \\
5 \mathrm{mg} \text { tab }\end{array}$ \\
\hline 7 & Amlodipine 5mg tab, Sanmol tab, Amoxan 500mg kaps \\
\hline 8 & Sanmol tab, Becom-C kapl, Amoxan 500mg kaps \\
\hline 9 & $\begin{array}{l}\text { Neurobion Forte tab, Clindamycin 300mg kaps, Amoxan } \\
500 \mathrm{mg} \text { kaps }\end{array}$ \\
\hline 10 & Becom-C kapl, Amlodipine 5mg tab, Neurobion Forte tab \\
\hline 11 & Amoxan 500mg kaps, Sanmol tab, Amlodipine 5mg tab \\
\hline 12 & Neurobion Forte tab, Amlodipine 5mg tab, Sanmol tab \\
\hline
\end{tabular}

Pembuatan Format Tabular berdasarkan data transaksi bulanan akan terlihat seperti tabel 14 dibawah ini. 
Tabel 14. Format Tabular Data Transaksi

\begin{tabular}{|c|c|c|c|c|c|c|}
\hline Bulan & Aml5 & Amox & Bcom & Clin & Neuf & Sann \\
\hline 1 & 0 & 0 & 1 & 1 & 0 & 1 \\
\hline 2 & 0 & 0 & 0 & 1 & 1 & 1 \\
\hline 3 & 1 & 1 & 0 & 0 & 0 & 1 \\
\hline 4 & 1 & 0 & 1 & 0 & 1 & 0 \\
\hline 5 & 0 & 1 & 0 & 1 & 0 & 1 \\
\hline 6 & 0 & 1 & 0 & 1 & 1 & 0 \\
\hline 7 & 1 & 1 & 0 & 0 & 0 & 1 \\
\hline 8 & 0 & 1 & 1 & 0 & 0 & 1 \\
\hline 9 & 0 & 1 & 0 & 1 & 1 & 0 \\
\hline 10 & 1 & 0 & 1 & 0 & 1 & 0 \\
\hline 11 & 1 & 1 & 0 & 0 & 0 & 1 \\
\hline 12 & 1 & 0 & 0 & 0 & 1 & 1 \\
\hline
\end{tabular}

Keterangan:

Aml5: Amlodipine 5mg tab

Amox: Amoxan tab

Bcom: Becom-C kapl

Clin: Clindamycin 300mg kaps

Neuf: Neurobion Forte tab

Sann: Sanmol tab

\section{Analisa Pola Frekuensi Tinggi}

\section{1) Pembentukan 1 Itemset}

Proses pembentukan $\mathrm{C} 1$ atau disebut dengan 1 itemset dengan jumlah minimum support $=30 \%$

Dengan menggunakan rumus:

$$
\operatorname{Support}(A)=\frac{\Sigma \text { Trnsaksi yang mengandung } A}{\Sigma \text { Transaksi }} * 100 \%
$$

Berdasarkan rumus tersebut maka pembentukan 1 itemset sebagai berikut:

$$
\begin{aligned}
& S(A m l 5)=\frac{\Sigma \text { Transaksi Aml5 }}{\Sigma 12}=\frac{6}{12} * 100 \%=50 \% \\
& S(\text { Amox })=\frac{\text { LTransaksi Amox }}{\Sigma 12}=\frac{7}{12} * 100 \%=58,33 \% \\
& S(\text { Bcom })=\frac{\Sigma \text { Transaksi Bcom }}{\Sigma 12}=\frac{4}{12} * 100 \%=33,33 \% \\
& S(\text { Clin })=\frac{\text { ETransaksi Clin }}{\Sigma 12}=\frac{5}{12} * 100 \%=41,66 \% \\
& S(\text { Neuf })=\frac{\text { LTransaksi Neuf }}{\Sigma 12}=\frac{6}{12} * 100 \%=50 \% \\
& S(\text { Sanm })=\frac{\Sigma \text { Transaksi Sanm }}{\Sigma 12}=\frac{8}{12} * 100 \%=66,66 \%
\end{aligned}
$$

\begin{tabular}{|c|c|c|}
\hline No & Itemset & Support \\
\hline 1 & Aml5 & $50 \%$ \\
\hline 2 & Amox & $58,33 \%$ \\
\hline 3 & Bcom & $33,33 \%$ \\
\hline 4 & Clin & $41,66 \%$ \\
\hline 5 & Neuf & $50 \%$ \\
\hline 6 & Sanm & $66,66 \%$ \\
\hline
\end{tabular}

Berdasarkan hasil diatas maka dapat dilihat pada tabel 15 dibawah ini.

Tabel 15. Support pembentukan 1 itemset

\section{2) Kombinasi 2 itemset}

Proses pembentukan $\mathrm{C} 2$ atau disebut dengan 2 itemset dengan jumlah minimum support $=30 \%$

Dapat diselesaikan dengan rumus :

Support $(\mathrm{A}, \mathrm{B})=\mathrm{P}(\mathrm{A} \cap \mathrm{B})$

$\operatorname{Support}(A, B)=\frac{\text { ETransaksi yang mengandung } A, B}{\Sigma \text { Transaksi }} * 100 \%$

Berdasarkan rumus tersebut maka pembentukan 2 itemset sebagai berikut:

Support $(\operatorname{Aml} 5$, Amox $)=\frac{3}{12} * 100 \%=25 \%$

$\operatorname{Support}(\mathrm{Aml} 5, \mathrm{Bcom})=\frac{2}{12} * 100 \%=16,66 \%$

Support $(\mathrm{Aml} 5, \mathrm{Clin})=\frac{3}{12} * 100 \%=25 \%$

$\operatorname{Support}(\mathrm{Aml} 5, \mathrm{Neuf})=\frac{0}{12} * 100 \%=0 \%$

$\operatorname{Support}(\mathrm{Aml} 5, \mathrm{Neuf})=\frac{3}{12} * 100 \%=25 \%$

Support $($ Aml5, Sanm $)=\frac{4}{12} * 100 \%=33,33 \%$

$\operatorname{Support}($ Amox, Bcom $)=\frac{1}{12} * 100 \%=8,33 \%$

Support $($ Amox, Clin $)=\frac{3}{12} * 100 \%=25 \%$

Support (Amox, Neuf) $=\frac{2}{12} * 100 \%=16,66 \%$

Support(Amox, Sann) $=\frac{5}{12} * 100 \%=41,66 \%$

Support $($ Bcom, Clin $)=\frac{1}{12} * 100 \%=8,33 \%$

$\operatorname{Support}($ Bcom, Neuf $)=\frac{2}{12} * 100 \%=16,66 \%$

$\operatorname{Support}($ Bcomn, Sanm $)=\frac{2}{12} * 100 \%=16,66 \%$

$\operatorname{Support}(\mathrm{Clin}, \mathrm{Neuf})=\frac{3}{12} * 100 \%=25 \%$

$\operatorname{Support}(\mathrm{Clin}, \mathrm{Sanm})=\frac{3}{12} * 100 \%=25 \%$

$\operatorname{Support}\left(\right.$ Neuf, Sanm) $=\frac{3}{12} * 100 \%=16,66 \%$

Berdasarkan hasil diatas maka dapat dilihat pada tabel 16 dibawah ini.

Tabel 16. Pembentukan Calon 2 itemset

\begin{tabular}{|c|l|l|}
\hline No & \multicolumn{1}{|c|}{ Itemset } & \multicolumn{1}{c|}{ Support } \\
\hline 1 & Aml5,Amox & $25 \%$ \\
\hline 2 & Aml5,Bcom & $16,66 \%$ \\
\hline 3 & Aml5,Clin & $0 \%$ \\
\hline
\end{tabular}




\begin{tabular}{|c|l|l|}
\hline 4 & Aml5,Neuf & $25 \%$ \\
\hline 5 & Aml5,Sanm & $33,33 \%$ \\
\hline 6 & Amox,Bcom & $8,33 \%$ \\
\hline 7 & Amox,Clin & $25 \%$ \\
\hline 8 & Amox,Neuf & $16,66 \%$ \\
\hline 9 & Amox,Sanm & $41,66 \%$ \\
\hline 10 & Bcom,Clin & $8,33 \%$ \\
\hline 11 & Bcom,Neuf & $16,66 \%$ \\
\hline 12 & Bcom,Clin & $16,66 \%$ \\
\hline 13 & Clin,Neuf & $25 \%$ \\
\hline 14 & Clin,Sanm & $25 \%$ \\
\hline 15 & Neuf, Sanm & $16,66 \%$ \\
\hline
\end{tabular}

Berdasarkan tabel 16 tersebut maka minimal support adalah $30 \%$, untuk itu itemset yangtidak memenuhi minimal support akan dihilangkan sehingga yang terbentuk adalah

Tabel 17 Hasil minimal Support 2 Itemset

\begin{tabular}{|c|l|c|}
\hline No & \multicolumn{1}{|c|}{ Itemset } & Support \\
\hline 1 & Aml5, Sanm & $33,33 \%$ \\
\hline 2 & Amox, Sanm & $41,66 \%$ \\
\hline
\end{tabular}

\section{3) Kombinasi 3 Itemset}

Proses pembentukan C3 dengan jumlah support $=30 \%$ Dapat diselesaikan dengan rumus:

$\operatorname{Support}(A, B, C)=\frac{\text { LTransaksi yang mengandung A, B, C }}{\Sigma \text { Transaksi }} * 100 \%$

Berdasarkan rumus tersebut maka pembentukan 3 itemset sebagai berikut:

Support(Aml5, Amox, Bcom) $=\frac{0}{12} * 100 \%=0 \%$

Support(Aml5, Amox, Clin) $=\frac{0}{12} * 100 \%=0 \%$

Support (Aml5, Amox, Neuf) $=\frac{0}{12} * 100 \%=0 \%$

Support(Aml5, Amox, Sanm) $=\frac{3}{12} * 100 \%=25 \%$

Support(Amox, Bcom, Clin) $=\frac{0}{12} * 100 \%=0 \%$

Support(Amox, Bcom, Neuf) $=\frac{0}{12} * 100 \%=0 \%$

Support(Amox, Bcom, Sanm) $=\frac{1}{12} * 100 \%=8,33 \%$

Support(Amox, Clin, Neuf) $=\frac{2}{12} * 100 \%=16,66 \%$

Support(Amox, Clin, Sanm) $=\frac{1}{12} * 100 \%=8,33 \%$

Support (Bcom, Clin, Neuf) $=\frac{0}{12} * 100 \%=0 \%$

Support $($ Clin, Neuf, Sanm $)=\frac{0}{12} * 100 \%=0 \%$

Berdasarkan hasil diatas maka dapat dilihat pada tabel 18 dibawah ini.

\begin{tabular}{|l|l|l|}
\multicolumn{3}{|c|}{ Tabel 18. Pembentukan Calon 3 Itemset } \\
\hline No & \multicolumn{1}{|c|}{ Itemset } & \multicolumn{1}{c|}{ Support } \\
\hline 1 & AM15,Amox,Bcom & $0 \%$ \\
\hline 2 & AM15,Amox,Clin & $0 \%$ \\
\hline 3 & AM15,Amox,Neuf & $0 \%$ \\
\hline 4 & AM15,Amox,Sanm & $25 \%$ \\
\hline 5 & Amox,Bcom,Clin & $0 \%$ \\
\hline 6 & Amox,Bcom,Neuf & $0 \%$ \\
\hline 7 & Amox,Bcom,Sanm & $8,33 \%$ \\
\hline 8 & Amox,Clin,Neuf & $16,66 \%$ \\
\hline 9 & Amox,Clin,Sanm & $8,33 \%$ \\
\hline 10 & Bcom,Clin,Neuf & $0 \%$ \\
\hline 11 & Bcom,Clin,Sanm & $0 \%$ \\
\hline 12 & Clin,Neuf,Sanm & $8,33 \%$ \\
\hline
\end{tabular}

Karena kombinasi 3 itemset tidak ada yang memenuhi minimal Support, maka 2 kombinasi itemset yang memenuhi untuk pembentukan asosiasi.

\section{4) Pembentukan Aturan Asosiasi}

Setelah semua pola frekuensi tinggi ditemukan, langkah selanjutnya adalah mencari aturan asosiasi yang memenuhi syarat confidence dengan menghitung confidence aturan asosiasi $\mathrm{A} \rightarrow \mathrm{B}$.

Minimal Confidence $=60 \%$

Nilai Confidence dari aturan $\mathrm{A} \rightarrow \mathrm{B}$ diperoleh dengan rumus: Confidence $=\mathrm{P}(\mathrm{B} \mid \mathrm{A})=$

$$
\frac{\Sigma \text { Transaksi yang mengandung A,B }}{\Sigma \text { Transaksi }} * 100 \%
$$

Berdasarkan rumus tersebut maka perhitungan confidence sebagai berikut:

$$
\begin{aligned}
& \text { Confidence }=\mathrm{P}(\text { Aml5 } \mid \text { Sanm })=\frac{4}{6} * 100 \%=66,66 \% \\
& \text { Confidence }=\mathrm{P}(\operatorname{Sanm} 5 \mid \mathrm{Aml} 5)=\frac{4}{8} * 100 \%=50 \% \\
& \text { Confidence }=\mathrm{P}(\text { Amox } \mid \text { Sanm })=\frac{5}{7} * 100 \%=71,43 \% \\
& \text { Confidence }=\mathrm{P}(\operatorname{Sanm} \mid \mathrm{Amox})=\frac{5}{8} * 100 \%=62,5 \%
\end{aligned}
$$

Dari kombinasi 2 itemset maka dapat dibentuk calon aturan asosiasi pada tabel 19 dibawah ini.

Tabel 19. Calon Aturan Asosiasi Final

\begin{tabular}{|l|l|l|}
\hline \multicolumn{1}{|c|}{ Aturan } & \multicolumn{2}{c|}{ Confidence } \\
\hline Jika membeli Aml5, maka akan membeli Sanm & $4 / 6$ & $66,66 \%$ \\
\hline Jika membeli Sanm, maka akan membeli Aml5 & $4 / 8$ & $50 \%$ \\
\hline Jika membeli Amox, maka akan membeli Sanm & $5 / 7$ & $71,42 \%$ \\
\hline Jika membeli Sanm, maka akan membeli Amox & $5 / 8$ & $62,5 \%$ \\
\hline
\end{tabular}

\section{5) Aturan Asosiasi Final}

Berdasarkan dari calon aturan asosiasi pada tabel 19 diatas maka yang memnuhi support $30 \%$ dan minimal confidence $60 \%$ dapat lihat pada tabel 20 dibawah ini.

\begin{tabular}{|l|l|c|}
\multicolumn{3}{|c|}{ Tabel 20. Aturan Asosiasi Final } \\
\begin{tabular}{|l|l|l|}
\hline \multicolumn{1}{|c|}{ Support } & Confidence \\
\hline $\begin{array}{l}\text { Jika membeli Aml5, maka akan } \\
\text { membeli Sanm }\end{array}$ & $33,33 \%$ & $66,66 \%$ \\
\hline $\begin{array}{l}\text { Jika membeli Amox, maka akan } \\
\text { membeli Sanm }\end{array}$ & $41,66 \%$ & $71,42 \%$ \\
\hline $\begin{array}{l}\text { Jika membeli Sanm, maka akan } \\
\text { membeli Amox }\end{array}$ & $41,66 \%$ & $62,5 \%$ \\
\hline
\end{tabular}
\end{tabular}

Dari pembahasan ini didapatkan hasil bahwa obat yang paling banyak terjual adalah Amoxan 500 mg kapsul, sanmol tablet dan amlodipine $5 \mathrm{mg}$ tablet. Dengan tingkat confidence tertinggi sebesar $71,42 \%$ dimana jika konsumen membeli obat amoxan $500 \mathrm{mg}$ pasti akan membeli sanmol tablet.

\section{KESIMPULAN}

Kesimpulan yang didapat pada penelitian ini adalah Obat yang paling sering dibeli oleh konsumen adalah amoxan 500 $\mathrm{mg}$, sanmol tablet dan amlodipine $5 \mathrm{mg}$. Jika membeli amoxan maka akan membeli sanmol dengan nilai confidence sebesar 
71, 42\%, jika membeli amlodipine maka akan membeli sanmol dengan nilai confidence sebesar $66,66 \%$, jika membeli sanmol maka akan membeli amoxan dengan nilai confidence $62,5 \%$ dan jika membeli sanmol akan membeli amlodipine dengan nilai confidence sebesar $50 \%$.

Pihak apotek mendapatkan informas tentang penjuala obat yang paling sering dibeli konsumen yaitu amoxan $500 \mathrm{mg}$, sanmol tablet dan amlodipine $5 \mathrm{mg}$. Sehingga pihak apotek perlu untuk menjamin ketersediaan dari jenis obat tersebut pada stok obat.

\section{REFERENCES}

[1] A. Valerian and L. Hakim, "Implementasi Algoritma Apriori Untuk Prediksi Stok Peralatan Tulis Pada Toko XYZ," J. Ilm. Teknol. Inf. Terap., vol. V, no. 1, pp. 18-22, 2018.

[2] M. R. Maulana, K. Kunci, : Sistem, P. Keputusan, and P. K. Karyawan, "PENILAIAN KINERJA KARYAWAN DI IFUN JAYA TEXTILE DENGAN METODE FUZZY SIMPLE ADDITIVE WEIGHTED,” J. Ilm. ICTech, no. 1, 2012.

[3] R. Yanto and R. Khoiriah, "Implementasi Data Mining dengan Metode Algoritma Apriori dalam Menentukan Pola Pembelian
Obat," Creat. Inf. Technol. J., vol. 2, no. 2, p. 102, 2015.

[4] Moh.Sholik and A. Salam, "Implementasi Algoritma Apriori untuk Mencari Asosiasi Barang yang Dijual di E-commerce OrderMas," Techno.COM, vol. 17, no. 2, pp. 158-170, 2018.

[5] A. Nursikuwagus and T. Hartono, "Implementasi Algoritma Apriori Untuk Analisis Penjualan Dengan Berbasis Web," Simetris J. Tek. Mesin, Elektro dan Ilmu Komput., vol. 7, no. 2, p. 701, 2016.

[6] E. Buulolo, "Algoritma Apriori Pada Data Penjualan Di Supermarket," Semin. Nas. Inov. dan Teknol. Inf. 2015, vol. 2015, no. September 2015, pp. 53-55, 2015.

[7] D. Listriani, A. H. Setyaningrum, and F. Eka, "PENERAPAN METODE ASOSIASI MENGGUNAKAN ALGORITMA APRIORI PADA APLIKASI ANALISA POLA BELANJA KONSUMEN (Studi Kasus Toko Buku Gramedia Bintaro)," J. Tek. Inform., vol. 9, no. 2, pp. 120-127, 2018.

[8] S. Kanti and R. E. Indrajit, "Implementasi Data Mining Penjualan Handphone Oppo Store Sdc Tanggerang Dengan Algoritma Appriori," Semin. Nas. Sains dan Teknol., no. November, pp. 1-2, 2017.

[9] Kusrini and E. T. Luthfi, Algoritma Data Mining. Yogyakarta: Andi Offset, 2009

[10] F. A. Hermawati, Data Mining. Yogyakarta: Andi, 2013.

[11] F. A. Sianturi, "Penerapan Algoritma Apriori Untuk Penentuan Tingkat Pesanan," Mantik Penusa, vol. 2, no. 1, pp. 50-57, 2018. 